\title{
Determination of Uric Acid by Chemiluminescence Measurement Using Tris(2,2'-bipyridine)ruthenium(II)-Octylphenylpolyglycol Ether System
}

\author{
Young-Sang Kim," Jeung Hee Park, and Yoon-seok Choi" \\ Department of Atwanced Material Chemistry, Korea University Jochiwon. Choongnam 339-700. Korea \\ ${ }^{\dagger}$ Wiest Sea Fisheries Research Institute, Kational Fisheries Research and Development Institute, Incheon $400-420$, Korea \\ Received April 13, 2004
}

\begin{abstract}
The determination of uric acid in urine samples was studied by a chemiluminescence measurement using tris (2.2'-bipy ridine)nthenium(II)-octylphenylpolyglycolether [Ru(bpy $\left.)^{2+}-\mathrm{OPE}\right]$ system. The oxidized uric acid by $\mathrm{Ce}$ (IV) excited Ru(bpy) $)_{3}^{2-}$ to emit a chemiluminescence in this system so that the intensity was stoichiometrically dependent upon the concentration of uric acid. In a reaction cell. a luminescent reagent. oxidant. surfactant and sulfuric acid were flowed into and mixed with a taken sample. Experimental conditions were optimized to obtain the maximum intensity of chemiluminescence. Each reactant solution of more than the following concentration gave a good result: $\left.2 \times 10^{-4} \mathrm{M} \mathrm{Ru(bpy}\right)_{s^{2-}}, 0.0 \mathrm{M} \mathrm{Me}$ (IV). $6 \%$ OPE. and $0.33 \mathrm{M}$ $\mathrm{H}_{2} \mathrm{SO}_{4}$. Any' interferences were not shown in this process by the investigation of concomitant constitutes such as albumin, creatine. lactic acid glucose. urea $\mathrm{Cl}^{-} . \mathrm{Mg}^{2-}, \mathrm{Ca}^{2-}$ and so on. The linearity of a calibration curve was good with $r=0.998$, the relative standard deviation of the slope was $3.3 \%$ and the detection limit was 5.6 $\mathrm{ng} / \mathrm{mL}$. The recoveries of 80 to $91 \%$ were obtained from the standard spiked samples. The values were little bit low but this procedure could be considered to be reliable for the determination of trace uric acid in urine samples.
\end{abstract}

Key Words : Chemiluminescence method, Uric acid. Flow injection. Tris(2,2'-bipyridine)ruthenium(II), Urine

\section{Introduction}

Recently the improvement of dietary life by an economical development causes over nutrient of high protein for the peoples so that the uric acid is increasing in a blood serum by a physiological reaction. Such phy'siological increase of uric acid is due to the over partaking of high protein foodstuffs and men's favorite foods. And the uric acid is also influenced by an over drinking of alcoholic beverages. an underexercise and a heavy stress.

The uric acid is the final metabolite of a purine base among the nucleic acids. That is. an inosine or guanosine is produced from the purine base in the biochemical reaction process and the product is converted to a xanthine which is oxidized to uric acid by the action of xanthine oxidase. The uric acid is excreted in a urine. In general. the patients indicate severe painful paroxy'sm by the high content of uric acid in the blood senum. but some of them do not. Therefore its accurate determination in a urine is very important to make a diagnosis of the first or second symptom of a gout. ${ }^{l}$

Brown's reduction method and an enzymatic method by urease are widely' used for the clinical determination of uric acid. But these methods have a high detection limit and are significantly tedious to process the procedure. Thus rapid and simple methods have been tried to obtain a accurate analytical result of the uric acid in real samples such as a urine

Among them. a few investigators have applied a chemiluminescence method for it. Kenichiro et al. " reported the determination method of the uric acid and glucose by the chemiluminescence reaction in a fixed enzy'me reactor.
Using an immobilized enzyme reactor. authors have conducted a rapid and sensitive flow-injection method by a peroxyoxalate chemiluninescence detection for the determination of glucose and uric acid. The proposed method showed good correlations between the results of serum glucose and uric acid assay. And Li et al. 'determined the uric acid by the chemiluminescence method using a potassium permanganate and a surfactant. That is. a fast and simple $\mathrm{KMnO}_{4}$-octylphenyl polyglycol ether chemiluminescence system was developed to be used for a high concentration of uric acid in urine sample with a flow injection analysis. The concentration of $\mathrm{KMnO}_{4}$ should be increased. But it showed a disadvantage of decrease of chemiluminescence intensity at a high permanganate concentration.

In addition. the chemiluminescence method became an interesting topic as a new analytical method because the method can provide a greatly good sensitivity to detect various kinds of analytes in many fields and can be conducted with a relatively simple structure of apparatus. And also it indicates a low background in the optical measurement with a simple system. Therefore. it is being widely used as a useful tool in a chemical analysis. Up to now. a continuous flow injection. ${ }^{412}$ liquid chromatography ${ }^{13-17}$ and capillary electrophoresis $(C E)^{18-2 l}$ have been mainly connected with the optical system. A very good selectivity and a very low detection limit could be accomplished with these kinds of connections.

In this study. a continuous flow injection system was used as a sample injection method and the determination of uric acid in urine sample was developed by the chemiluminescence method using Ru(bpy) $)^{2-}$ as a chemiluminescent reagent. It 
was known that our system had a wide dynamic range of calibration curve by using $\mathrm{Ce}(\mathrm{IV})$ as an oxidant instead of $\mathrm{KMnO}_{4}$. The chemical reactions to emit the chemiluminescence in the system of Ru(bpy): ${ }^{2+}-\mathrm{OPF}-\mathrm{Ce}(\mathrm{IV})$ can be written as follows:

$$
\begin{aligned}
& \text { Uric acid }+\mathrm{Cc}(\mathrm{IV})-\mathrm{U} \text { ric acid } \cdot+\mathrm{Cc}(\mathrm{III}) \\
& \text { Ru(bpy) })_{3}^{3-} \text { । Uric acid - - } \\
& \left.[\text { Ru(bpy })_{3}^{2 !}\right]^{*}+\text { Uric acid fragments }+\mathrm{H}^{\text {. }} \\
& {\left[\mathrm{Ru}(\mathrm{bpy})_{\xi}^{2{ }^{\prime}}\right]^{*}=\mathrm{Ru}(\mathrm{bpy})_{\xi}^{2 \cdot}+h v}
\end{aligned}
$$

In this scheme, the oxidized uric acid reacts with $\mathrm{Ru}$ (bpy) ${ }_{3}{ }^{3-}$ in the process to emit radiations.

One kind of surfactant, octylphenylpolyglycol ether (OPF), plays an important role to excite Ru(bpy) ${ }_{3}{ }^{2-}$ by the reaction with uric acid radical. Therefore, the mixed solution of OPE: with Ru(bpy) ${ }_{3}^{2-}$ is simultaneously sent to the coil. Under the conditions of excess existence of other reagents, the luminescent intensity depends upon the concentration of uric acid, proportionally. The fact provides the theory for the determination of uric acid by the chemiluminescence method.

And the chemiluminescence intensity was much improved by adding OPF a surfactant. The OPE: has a strong tendency to form micelle in an acjueous solution by the association of themselves. Most common substances in biological samples not interfered with this system except $\mathrm{Fe}^{\mathrm{i+}}$, so this method could be applicable in clinical sample analysis without any pre-treatment of real urine sample. Useful results were obtained by applying this system for the analysis of real human urine samples so that the results are introduced here.

\section{Experimental Section}

Reagents and apparatus. A deionized water was used. The deionized water was produced by the purification of 1 st distilled water with Millipore Milli-Q water system. All reagents of $\mathrm{Ru}(\text { bpy })_{3} \mathrm{Br}_{2}$, uric acid. $\mathrm{H}_{2} \mathrm{SO}_{4}$, octylphenylpolyglycol ether (OPE), Tween 20, Tween 80. TX-100, sodium lauryl sulfate, Span 80 , cetyltrimethyl ammonium bromide, urea. Lascorbic acid, gluthathion, tryptophan, cystein, albumin. creatine, lactic acid and glucose were the reagent grade of Aldrich Co., U.S.A. and were used without the further purification. Hydrochloric acid and nitric acid were of Merck Co.. Germany.

Our laboratory-built instrument was used to measure the chemiluminescence intensity (Figure 1). A peristaltic pump of EYELA Co. was used to pump and flow each solution through the teflon tube of i.d. $1.15 \mathrm{~mm}, 0 . d$ and $3.2 \mathrm{~mm}$ to the reaction coil. A photomultiplier at $-700 \mathrm{~V}$ was used to detect the intensity of chemiluminescence and the signal from the PM tube was amplified by self-manufactured loc-in amplifier and was transferred to a current to voltage converter. The analog signal was converted to digital signal by $\mathrm{PCL}$ $816 \mathrm{~A} / \mathrm{D}$ converter of Advantech Co., U.S.A. Every function

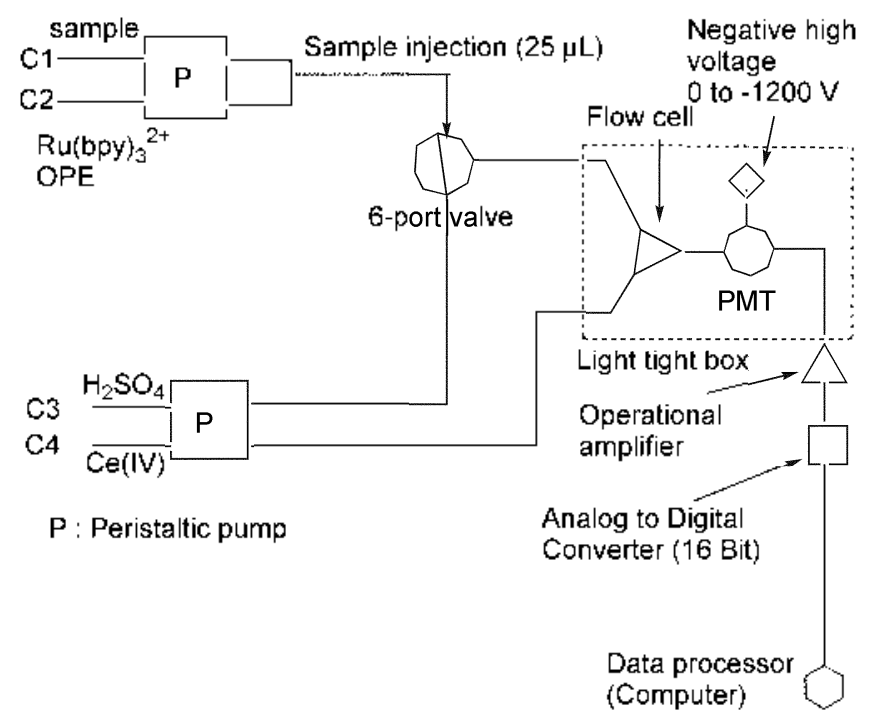

Figure 1. Schematic diagram of how-injection chemiluminescence (CI.) system for the determination of uric acid.

was operated with a 16 bit desk-top computer. Model PHM$2000 \mathrm{pH}$ meter of Tokyo Rikakikai Co., Japan was used with Ingold composite glass electrode and the meter was calibrated with a buffer solution before used.

Measurement of chemiluminescence intensity. A sample solution was flowed into a reaction coil through $C 1$ of the system and the flow rate was adjusted to fix the total flowing time of 5 minutes. The mixed solution of $\mathrm{Ru}(\mathrm{bpy})_{3}{ }^{2-}$ and octylphenylpolyglycol ether (OPF) was flowed through $\mathrm{C}$ 2 and $\mathrm{H}_{2} \mathrm{SO}_{4}$ solution was injected through $\mathrm{C} 3$. Ce(IV) solution was used as an oxidant and the solution was provided in the coil through $C 4$ teflon tube of i.d. $1.15 \mathrm{~mm}$ and o.d. $3.2 \mathrm{~mm}$. The total mixing time in $60 \mathrm{~cm}$ reaction coil was fixed with 10 seconds and the flow rate of a sample solution was adjusted with a peristaltic pump to fix the total flowing time of 2 minutes. And the injection valve was composited with 6 ports and each injection volume of the sample solution was $25 \mu \mathrm{L}$.

\section{Results and Discussion}

Effect of $\mathrm{Ru}(\mathrm{bpy})_{3}{ }^{2+}$ concentration. The concentration and flowed volume of each reagent solution were investigated to obtain the maximum luminescent intensity by this continuous flow system. The standard solution of uric acid was injected into coil through $\mathrm{Cl}$, the mixed solution of $\mathrm{Ol} \mathrm{P}^{\mathrm{E}}$ and $\mathrm{Ru}(\text { bpy })_{3}{ }^{{ }^{3}}$ through $\mathrm{C} 2$, an acid through $\mathrm{C} 3$, and a $\mathrm{Ce}$ (IV) oxidant solution through $\mathrm{C} 4$. The experiment was conducted at flow rate of $0.31 \mathrm{~mL} / \mathrm{min}$ for each solution with the injection tube of given specifications. The maximum intensity was emitted at 10 second of the reaction time in the reaction coil of $60 \mathrm{~cm}$.

The Ru(bpy) $)_{3}{ }^{2 \cdot}$ was excited to $\left[\mathrm{Ru}(\mathrm{bpy})_{5^{2}}\right]^{*}$ by the reaction with the oxidized uric acid. The uric acid was oxidized by $\mathrm{Ce}(\mathrm{IV})$ before their mixing. And the excited $\left[\mathrm{Ru}(\mathrm{bpy})_{5}{ }^{2}{ }^{2}\right]^{*}$ returned to the ground state to emit a radiation. 'The radiation intensity was dependent on the concentration of $\left[\mathrm{Ru}(\mathrm{bpy})_{3}{ }^{2}\right]^{*}$ 
which was proportional to the concentration of uric acid. In this case, it was known that the excited $\left[\mathrm{Ru}(\mathrm{bpy}) \mathrm{s}^{2-}\right]^{*}$ could emit the chemiluminescence more effectively. Under other optimized conditions, the effect of $\mathrm{Ru}(\mathrm{bpy}) \mathrm{s}^{2+}$ concentration on the chemiluminescence intensity of $1.0 \mathrm{mg} / \mathrm{ml}$, uric acid solution was investigated varying the concentration of $\mathrm{Ru}$ (bpy) $s^{2-}$ up to $0.002 \mathrm{M}$ (Figure 2). The maximum intensity was shown from $2 \times 10^{-1} \mathrm{M} \mathrm{Ru}(\text { bpy })_{3}{ }^{2+}$.

Concentration of oxidant, Ce(IV). The oxidized uric acid can quantitatively excite $\mathrm{Ru}(\mathrm{bpy})_{3}{ }^{{ }^{2-}}$ to emit the chemiluminescence so that the uric acid also should be quantitatively oxidized with a proper oxidant. Ce(IV) was used as a strong oxidant in this experiment. The chemiluminescence intensity of each $1.0 \mathrm{mg} / \mathrm{ml}$, uric acid solution was measured changing the concentration of $\mathrm{Ce}(\mathrm{IV})$ as an oxidant up to $0.05 \mathrm{M}$ (Figure 3). The measurement was done under other optimized conditions. As shown in figure, the constant intensity was shown from $0.01 \mathrm{M}$ Ce(IV) concentration.

Type and concentration of surfactant. An amphiphilic surfactant usually forms micelles in an aqueous solution at the concentration of more than critical micelle concentration (CMC). Such a partially micro environmental micelle system is quitely different with a nonnal bulky solvent system. Therefore, such micelles signiticantly affect the chemiluminescence intensity. On the other hand, the intensity is also influenced by the polarity, viscosity and dielectric constant of a solvent. but the formation of micelles by a surfactant is known to decrease such influences by the formation of a protective enviromment for the singlet state of a chemiluminescence emitter, In general, the micro environment provided by such micelles enhances the chemiluminescence.

In this work, the chemiluminescence intensity by the proposed system was measured using the various types of cationic, anionic and neutral surfactants. The net intensity could be obtained only in the presence of octylphenylpolygrycolether (OPE) as shown in Table 1.

Because the chemiluminescence intensity was increased

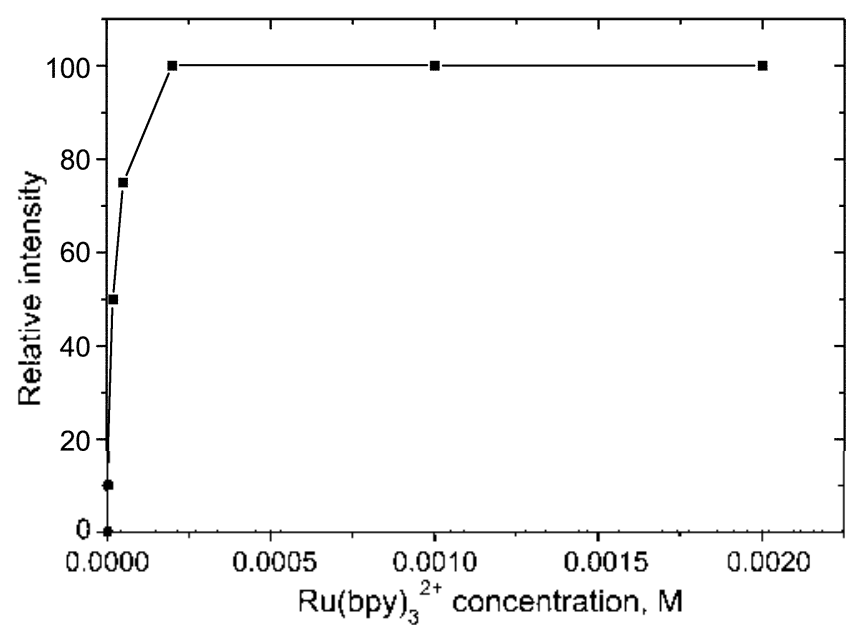

Figure 2. Liffect of Ru(bpy); ${ }^{21}$ concentration on chemiluminescence intensity of $1.0 \mathrm{mg} / \mathrm{mL}$ uric acid under other optimized conditions. OPF : $6 \%(\mathrm{v} / \mathrm{v}) . \mathrm{Ce}(\mathrm{IV}): 0.01 \mathrm{M} . \mathrm{H}_{2} \mathrm{SO}_{4}: 0.33 \mathrm{M}$

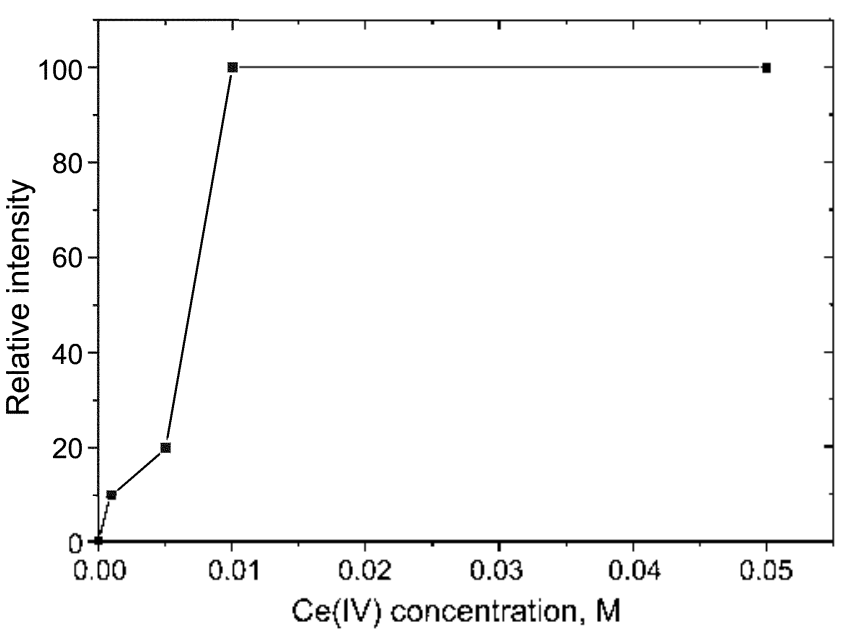

Figure 3. Effect of $C(I V)$ concentration on the ehemiluminescence intensity of $1.0 \mathrm{mg} / \mathrm{mL}$ uric acid under other optimized conditions. Ru(bpy) $3^{2-}: 2 \times 10^{-1}$ M. OPF : $6 \%(\mathrm{v} / \mathrm{v}), \mathrm{H}_{2} \mathrm{SO} \mathrm{O}_{+}: 0.33$ $\mathrm{M}$.

by adding OPE in this system, the increase of intensity was also investigated increasing the OPF concentration up to 10 $\%(v / v)$. As shown in Figure 4, the intensity was increased up to $5 \%(\mathrm{v} / \mathrm{V})$ and a constant intensity was kept at higher concentration than the $\mathrm{CMC}$ of $\mathrm{OP}\left[, 1.3 \times 10^{-3} \mathrm{M}\right.$. The intensity increase up to $5 \%$ could be considered to be due to the expansion of micro environments by the formation of micelles.

Type and concentration of acid. As described in previous section, Ce(IV) was used as an oxidant. Because the $\mathrm{Ce}(\mathrm{IV})$ could more strongly oxidize other chemical species in an acidic solution, the oxidation power of $\mathrm{Ce}$ (IV) to uric acid was investigated with various acids of sulfuric acid, phosphoric acid, hydrochloric acid and nitric acid (Figure 5). The maximum and stable intensity was emitted in sulfuric acid solution among them. Also other acids have helped to emit the chemiluminescence, but the intensities were less than sulfuric acid.

And the relative intensity was measured up to $2.0 \mathrm{M} \mathrm{H}_{2} \mathrm{SO}_{4}$ to investigate the concentration dependency on the chemiluminescence (Figure 6). The constant intensity was shown in a

Table 1. Type of surlactants for the chemiluminescence sy stem

\begin{tabular}{|c|c|}
\hline Surfactant & $\begin{array}{c}\text { Chemilumineseence intensity } \\
\text { (arbitrary value) }\end{array}$ \\
\hline CPC: & - \\
\hline $\mathrm{CIAl}^{\circ}$ & - \\
\hline Span 20 & - \\
\hline Span 80 & - \\
\hline $1^{\prime} X-100^{*}$ & - \\
\hline $\operatorname{SIS} S^{*}$ & - \\
\hline liveen 20 & - \\
\hline liveen 80 & - \\
\hline Ol' & 3 \\
\hline
\end{tabular}

"CIAB: cetyltrimethyl ammonium bromide. IX-100: Iriton X-100. SI.S: sodium lauryl sulfate, (-): Background signal 


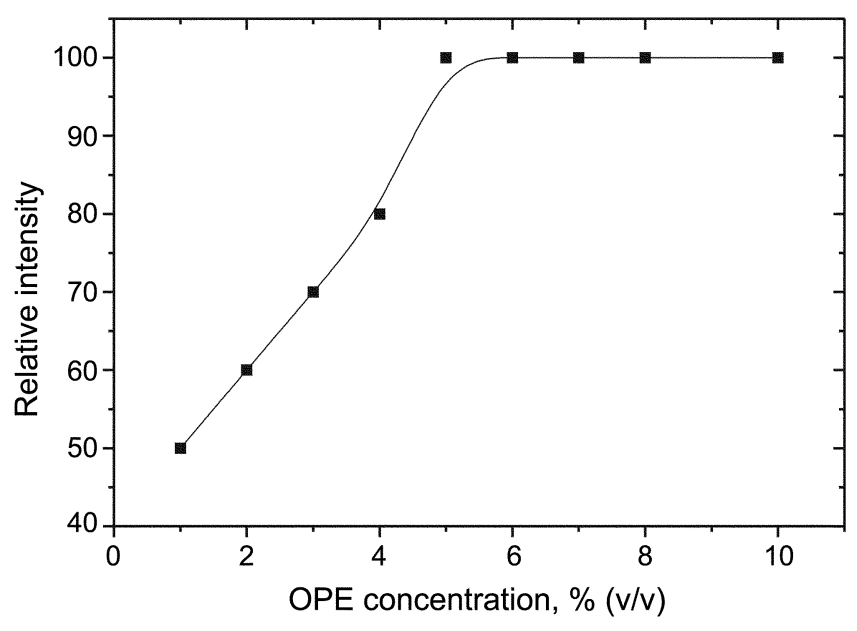

Figure 4. Leffect of the OPE concentration on the C.L intensity of $1.0 \mathrm{mg} / \mathrm{mL}$ uric acid under other optimized conditions. Ru(bpy $)_{3}{ }^{\prime 1}$ : $2 \times 10^{-1} \mathrm{M}, \mathrm{Ce}(\mathrm{JV}): 0.01 \mathrm{M}_{2} \mathrm{H}_{2} \mathrm{SO}_{4}: 0.33 \mathrm{~V}$.

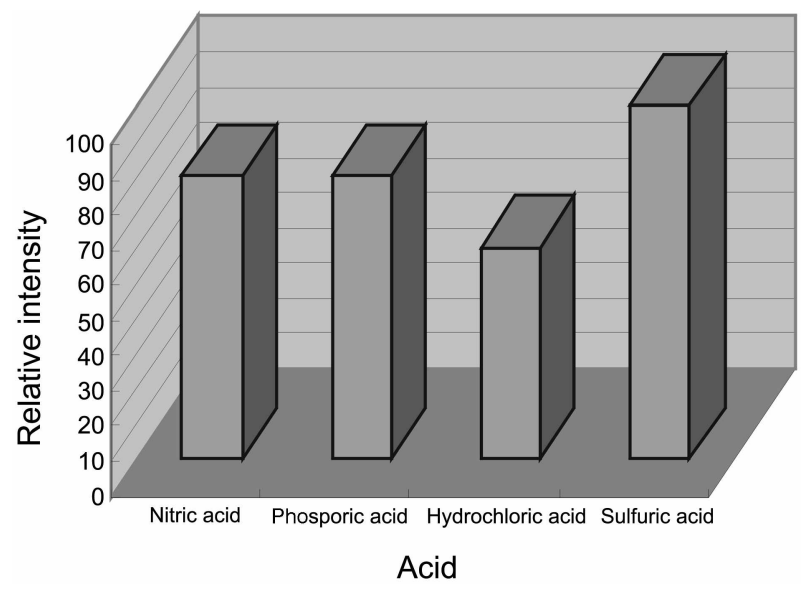

Figure 5. Effect of acid on the chemilumineseence intensity of 1.0 $\mathrm{mg} / \mathrm{ml}$, uric acid under other optimized conditions. Ru(hpy $)_{3}{ }^{++}: 2$ $\times 10{ }^{4} \mathrm{M}$. Ce(IV): $0.01 \mathrm{M}$, OPI: : $6 \%(\mathrm{v} / \mathrm{v})$.

relatively strong acidic solution of more than $0.33 \mathrm{M} \mathrm{H}_{2} \mathrm{SO}_{4}$. Ihis phenomenon was consistent to the fact that $\mathrm{Ce}$ (IV) could strongly oxidize some species of reducing agents in acidic solution.

Interferences of concomitant species. The interferences of some possibly coexisted species were investigated to know if the selective determination of uric acid could be done by the method proposed previously. Eight kinds of bioorganic compounds and six inorganic elemental ions which were known to be existed in urines were selected as interfering species. Each chemical species was added to uric acid solution to make the concentration $1,10,100$ and 1,000 $\mathrm{g} / \mathrm{mL}$. And the chemiluminescence intensities of $1.0 \mathrm{mg} / \mathrm{mL}$ uric acid were measured by a given system under optimized conditions. The results were listed in Table 2 .

As shown in lable 2. bioorganic compounds of albumin, creatine, lactic acid and glucose and inorganic ions of $\mathrm{Cl}^{-}$. $\mathrm{Mg}^{2-}$ and $\mathrm{Ca}^{2-}$ have not interfered with the intensity measurement of uric acid even their concentration was more than $1,000 \mathrm{~g} / \mathrm{mL}$. $\mathrm{Al}^{3+}$ and $\mathrm{Zn}^{2-}$ ions did not interfere with the

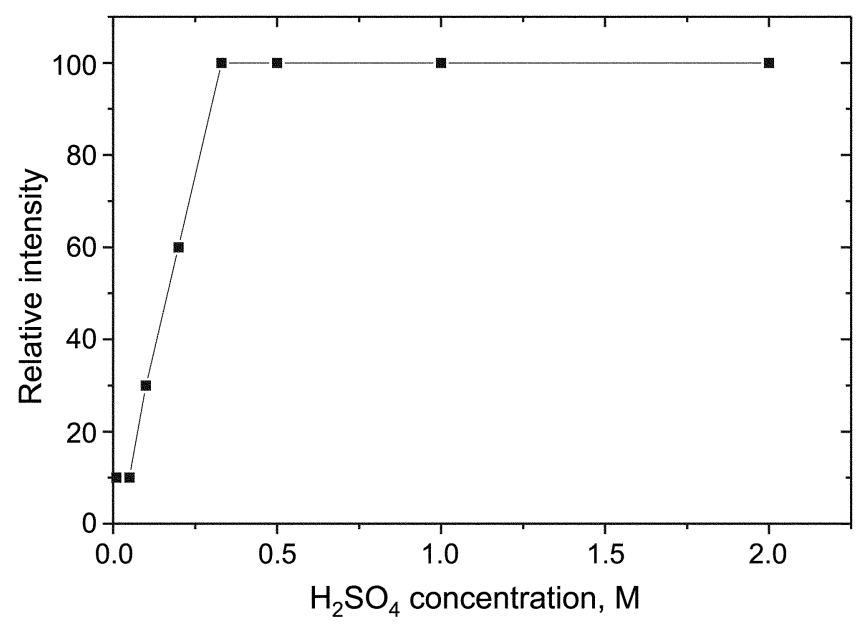

Figure 6. Fillect of $\mathrm{H}_{2} \mathrm{SO}_{4}$ concentration on the chemiluminescence infensily. Ru(bpy); ${ }^{2-}$ : $2 \times 10^{-4}$ M. Ce(IV) : $0.01 \mathrm{M}$. OPl: : $6 \%(v / v)$.

Table 2. Tolerable concentration with respect to $1.0 \mathrm{\mu g} / \mathrm{ml}$ : uric acid for some interfering species

\begin{tabular}{cc}
\hline Substance & lolerable concentration \\
\hline Albumin. Creatine. Iactic acid. Glucose & $>1000 \mu \mathrm{g} / \mathrm{ml}$ \\
Urea & $>1000 \mu \mathrm{g} / \mathrm{ml}$ \\
$\mathrm{Cl}^{-}$ & $>1000 \mu \mathrm{g} / \mathrm{ml}$ \\
$\mathrm{Mg}^{2-} \cdot \mathrm{Ca}^{2+}$ & $>1000 \mu \mathrm{g} / \mathrm{ml}$ \\
\hline $\mathrm{Al}^{51} \cdot 7 \mathrm{n}^{21}$ & $100 \mu \mathrm{g} / \mathrm{ml}$ \\
\hline L-ascorbic acid. Gluthathion & $10 \mu \mathrm{g} / \mathrm{mL}$ \\
\hline Cysteinc. Fc & $1 \mu \mathrm{g} / \mathrm{mL}$
\end{tabular}

measurement up to $100 \mu \mathrm{g} / \mathrm{ml}$, and $\mathrm{I}$-ascorbic acid and gluthathion also did not interfere up to $10, \mu \mathrm{g} / \mathrm{ml}$. But cysteine and $\mathrm{Fe}^{3+}$ ion affected the intensity at more than 1 $\mu \mathrm{g} / \mathrm{ml}$.

Determination of uric acid in real urine samples. In order to evaluate the usefulness of this developed procedure,

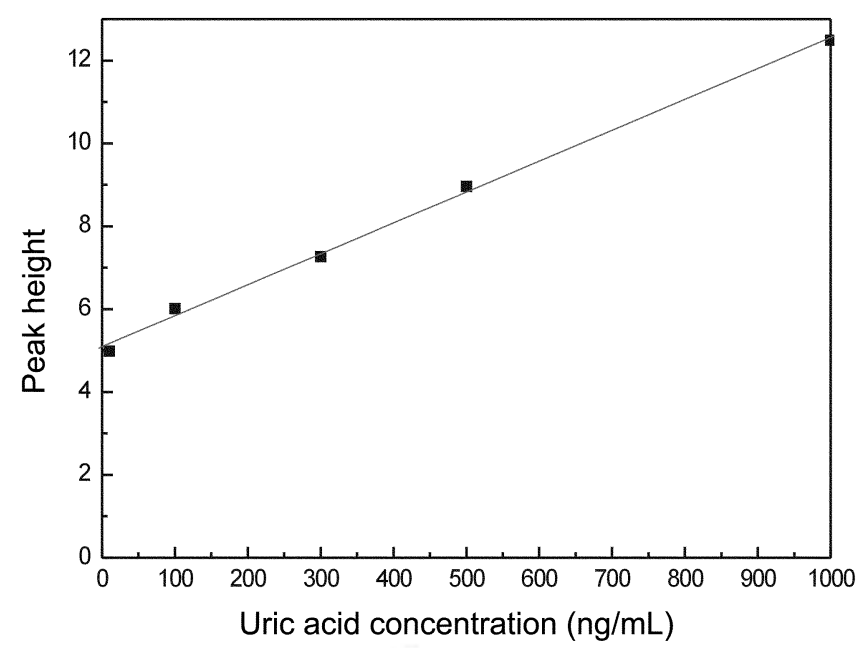

Figure 7. Calibration curve for the deternination of uric acid by the proposed mithod. 
Table 3. Uric acid measurements in human urine samples

\begin{tabular}{ccccc}
\hline Sample & $\begin{array}{c}\text { Uric acid added } \\
(\mu \mathrm{g} / \mathrm{mL})\end{array}$ & $\begin{array}{c}\text { Measured } \\
(\mu \mathrm{g} / \mathrm{mL})\end{array}$ & $\begin{array}{c}\text { Recovered } \\
(\mu \mathrm{g} / \mathrm{mL})\end{array}$ & $\begin{array}{c}\text { Recovery } \\
(\%)\end{array}$ \\
\hline Menl-a & 0.00 & 326.05 & & \\
Men-b & 100.00 & 413.27 & 87.22 & 87.22 \\
& 0.00 & 440.56 & & \\
Menl-c & 100.00 & 521.35 & 80.79 & 80.79 \\
& 0.00 & 658.22 & & \\
Men-d & 100.00 & 742.39 & 84.17 & 84.17 \\
& 0.00 & 527.56 & & \\
Menl-e & 0.00 & 596.25 & & 83.31 \\
& 100.00 & 677.69 & 81.44 & 81.44 \\
Womnen-a & 0.00 & 246.97 & & \\
& 100.00 & 335.46 & 88.49 & 88.49 \\
Women1-b & 0.00 & 335.85 & & \\
& 100.00 & 420.59 & 84.74 & 84.74 \\
Womnen-c & 0.00 & 430.87 & & \\
& 100.00 & 532.98 & 82.11 & 82.11 \\
Women1-d & 0.00 & 299.74 & & \\
& 100.00 & 390.68 & 90.94 & 90.94 \\
Women-e & 0.00 & 363.77 & & \\
& 100.00 & 452.14 & 88.37 & 88.37 \\
\hline
\end{tabular}

Results presented are mean values of three determinations $(n=3)$. "Recovery test was carried out by spiking the uric acid standard solution to the real samples.

uric acid was deternined in real human urine samples by the optimized conditions. Five uric acid standard solutions of 10.0 to $1,000 \mathrm{ng} / \mathrm{mL}$ were prepared with a little modified water. The measured intensity under the given conditions was plotted versus the concentration of uric acid to prepare a calibration curve (Figure 7). The linearity was good with $\mathrm{r}=$ 0.998 , the relative standard deviation of the slope was $3.3 \%$ and the detection limit was $5.6 \mathrm{ng} / \mathrm{mL}$.

Urine samples were taken from five healthy male and female persons of twenties to forties ages. The $1.0 \mathrm{~mL}$ of each urine sample was diluted to $10.00 \mathrm{~mL}$ in volumetric flask with deionized distilled water and the chemiluminescence intensities of the samples treated with the proposed conditions were measured to obtain the contents in urines (Table 3). In addition, recovery tests were done for the evaluation of this proposed procedure. Standard uric acid was spiked to become the added concentration to $100 \mu \mathrm{g} / \mathrm{mL}$ in samples. The percent recovery values were obtained by subtracting uric acid contents in real samples from the contents in spiked samples. As shown in table. this method can be considered to be applicable to real analy sis because of complex luminescence reactions and delicate procedure even though the recovery values of 80 to $91 \%$ are little bit low.

Acknowledgement. This work was supported by The Korea Research Foundation with Grant Number KRFDP0217. The support should be sincerely appreciated by researchers.

\section{References}

1. Burtist. C. A.: Ashwood. E. R. Tietz Texthook of Clinical Chentistry, 2nd ed: WB Saunders Company: Philadelphia. 1994; p 1539.

2. Kenichiro. N.: Naoko, H, Shinki, K.: Shuzo. A.: Yukie, T: Kazuhiro. I. Anal. Sci. 1991. 7.715.

3. Li. Z:: Feng. M.: Lu. J. Mficrochem. J. 1998. 59. 278

4. Inndadullah. Terufumni F.: Takahiro. K. And. Chem. 1991. 63. 2348.

5. Qun. F.: Xiao-Tong, S.: Yu-Qing. S.; Zhao-Lun. F. Anal. Chent. 1997. 69,3570 .

6. Wei. Q.: Zhuhut1. Z.: Huajun. L. Anal Chem. 1998. 70. 3579.

7. Jinchut1. Y.: Alan. M. S. Anal. Chem. 1999. 71. 1975.

8. Nobutoshi. K.: Hidekazu. K.: Motohisa. F. And. Sci. 1995. 11. 605 .

9. Takashi. H.; Junko, N.: Takuji. K. Anal. Sci, 1997, 13,93.

10. Theingi. K.: Terufumi, F.: Fidekazu. I.: Yasuaki. O.: Takahiro, K. Anal. Sci. 1998. 14.203.

11. Kazuhiko. T.: Masayuli. S.: Riichiro. N.: Masamichi. N.: Mizuo. M. Anal. Sci. 1998. 14. 409.

12. Kazunori. I.: Hideaki. W. Isao, K. Biosensor 1996. 11, 959.

13. Juana C.: Manuel, S: Dolores, P. Anal Chem. 1995. 67, 4376.

14. Pablo, P; Romofumi, S; Hiroshi. H; Kazuhiro. I. Anal Sci. 1995. 11.575 .

15. Ryoya. G.: Kohsuke. K.: Tomot.fumi. S.: Takeshi. F. Anal. Sci. 1996. 12.713

16. Mitsuhiro, W.: Naotaka, K: Toshihiko, I.: Shuzo. A.: Kenichiro. N. Anal. Sci. 1996. 12.807

17. Kazuichi. H:- Tsuyoshi, M.; Mizuka. B.; Motoichi. M. Eniron. Sci. Tech. 1995. 29.928.

18. Bo. H.: Tian-j. L.: Le. Z.: Jie-ke. C. Anal. Chem. 1996. 68. 2366.

19. Kuimala. S.: Ala-Kleme. T.: Papkorsky. D.: Loikas. K. Anat Chent $1998,70,1112$.

20. Kazuhiko, T; Shigehiro. F.; Riichiro, N. Anal. Sci. 1997, 13. 279.

21. Tadashi. H.: Syuji, K.; Hishshi. N.: Riichiro. N. Anal. Sci. 1994. 10. 223. 